\title{
Surgical Technique for Palsy of Superior Division of Oculomotor Nerve
}

\author{
Birsen Gokyigit, Selcen Celik, Asli Inal \\ University of Health Sciences Prof. Dr. Resat Belger Beyoglu Eye Research and Training Center, Istanbul, Turkey
}

\begin{abstract}
This report is a description of a new surgical technique for palsy of the superior division of the oculomotor nerve. A 52-year-old female who had previously been operated on for an intracranial tumor described ocular motility restriction. A complete ophthalmological examination revealed elevation deficiency of -4 and accompanying ptosis in the left eye. Botulinum toxin injection was administered, and recession of the inferior rectus muscle, and tucking of the superior rectus following union of the medial and lateral rectus muscles were performed. In our technique, no scleral suture was used during the union of muscles procedure. Postoperatively, elevation improved significantly and hypotropia was fully corrected. In addition to being as effective as the previously described Knapp procedure, our technique is safer and easier. Keywords: Muscle transposition, superior rectus palsy, superior rectus tucking, sutureless technique.
\end{abstract}

\section{Introduction}

The diagnosis and management of third nerve dysfunction varies according to the age of the patient, characteristics of the third nerve palsy, and the presence of associated symptoms and signs. Third nerve palsy may be partial or complete, congenital or acquired, isolated or accompanied by signs of more extensive neurological involvement. It can result from lesions located anywhere from the oculomotor nucleus to the termination of the third nerve in the extra-ocular muscles within the orbit. The superior division runs forward intraconally to innervate first the superior rectus first and then the levator above on its inferior surface.

Isolated paralysis of the superior rectus muscle is most commonly congenital, but may also be secondary to trauma (I). The paralyzed eye is affected primarily in abduction and elevation, and is hypotropic in the primary position.

\section{Surgical Technique}

This study was approved by the institutional review board. Written informed consent was obtained from the patient and the study adhered to the tenets of the Declaration of Helsinki.

A 52-year-old female presented at the clinic with ocular motility disturbance and ptosis in the left eye (Fig. I.) She had previously been operated on for an intracranial tumor. Ocular motility disorder occurred following the surgery. The initial evaluation included a comprehensive medical history and complete ophthalmological examination, including assessment of visual acuity, ocular motility, cycloplegic refraction, and examination of anterior and posterior segments. The Krimsky test was used to assess deviation at both near and distance fixation. Ductions and versions were quantified on the following 4-point scale of $-I$ to -4 : $-I$ is mild limitation, -2 is moderate limitation, -3 is severe limitation,

Address for correspondence: Birsen Gokyigit, MD. Beyoglu Goz Egitim ve Arastirma Hastanesi, Bereketzade Cami Sokak, 34421 Beyoglu, Istanbul, Turkey

Phone: +90 5322463799 E-mail: bgokyigit@hotmail.com

Submitted Date: July 23, 2017 Accepted Date: August 23, 2017 Available Online Date: October 16, 2017

${ }^{\circ}$ Copyright 2017 by Beyoglu Eye Training and Research Hospital - Available online at www.beyoglueye.com 

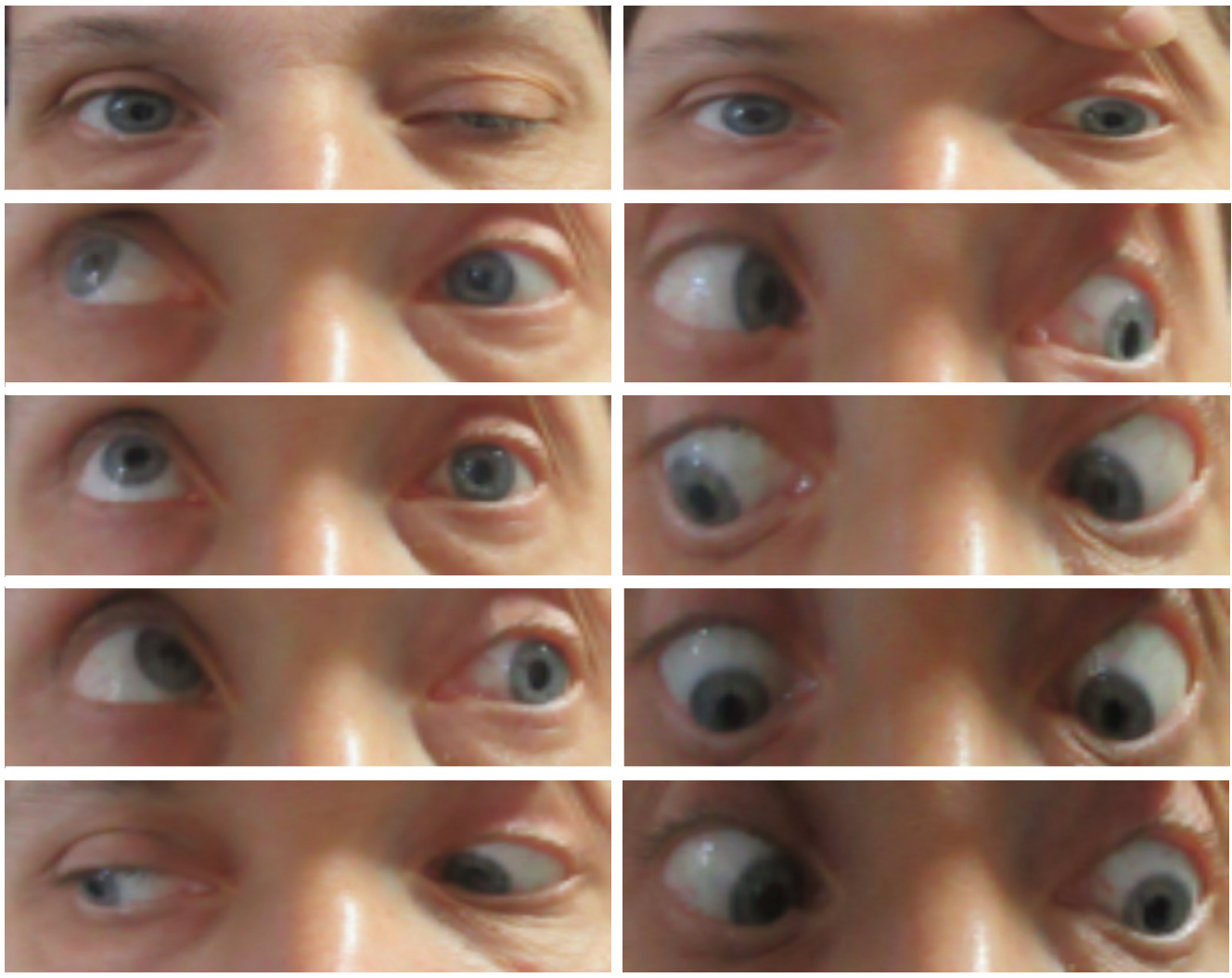

Figure I. Preoperative photos of the patient.

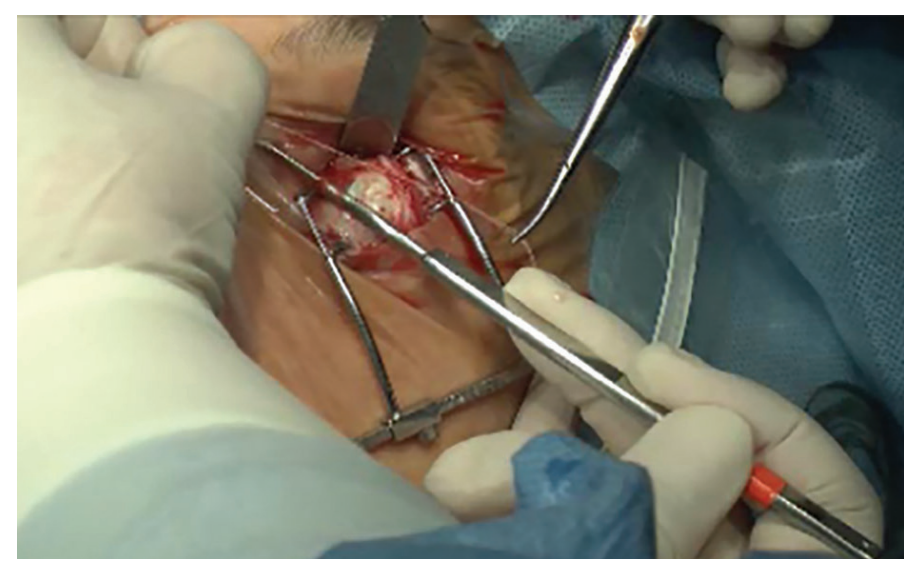

Figure 2. The medial and lateral rectus muscles were apposed with the help of the previously placed Dacron sutures

and -4 is no elevation above primary position. Visual acuity was $I .0$ in the right eye and refraction was +0.50 . Anterior and posterior segment examination and ocular motility were normal. In the left eye, visual acuity was counting fingers and cycloplegic refraction was +1.50 . Biomicroscopic evaluation of the anterior segment showed ptosis of the upper eyelid and posterior segment evaluation revealed optic nerve pallor. Ocular motility was completely restricted in elevation and recorded as -4 . Ocular deviation was recorded as 30 prism diopters (PD) of hypotropia in the left eye at both near and distance fixations according to the Krimsky test.

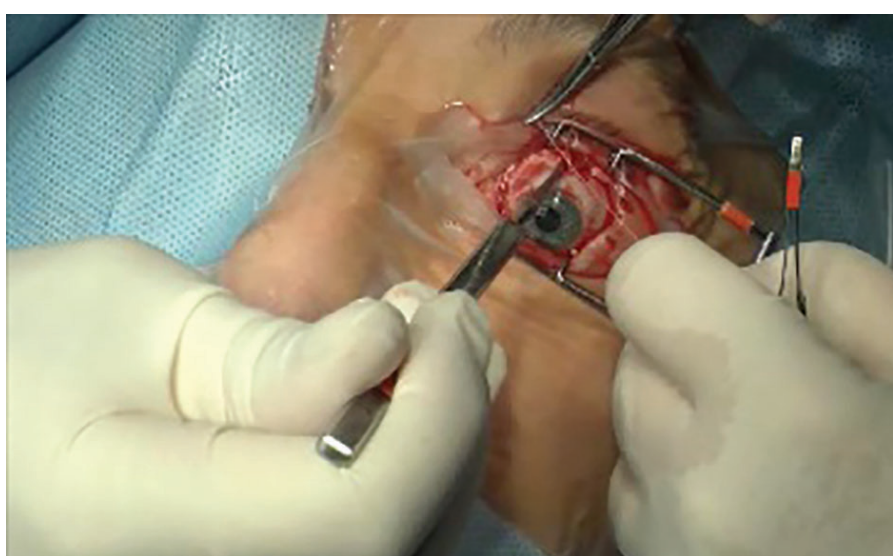

Figure 3. Superior rectus plication under the muscle union

After a botulinum toxin injection, a 7-mm recession of the inferior rectus was performed, followed by surgery that included superior rectus tucking and union of the medial and lateral rectus muscles.

\section{Surgical Technique}

Conjunctival incision was performed at the limbus between the 4 and 8 o'clock positions, and the medial rectus, lateral rectus, and superior rectus muscles were exposed with dissection. A 6/0 Dacron (Invista North America SARL, Wichita, KS, USA) suture was used to grasp one-seventh width 

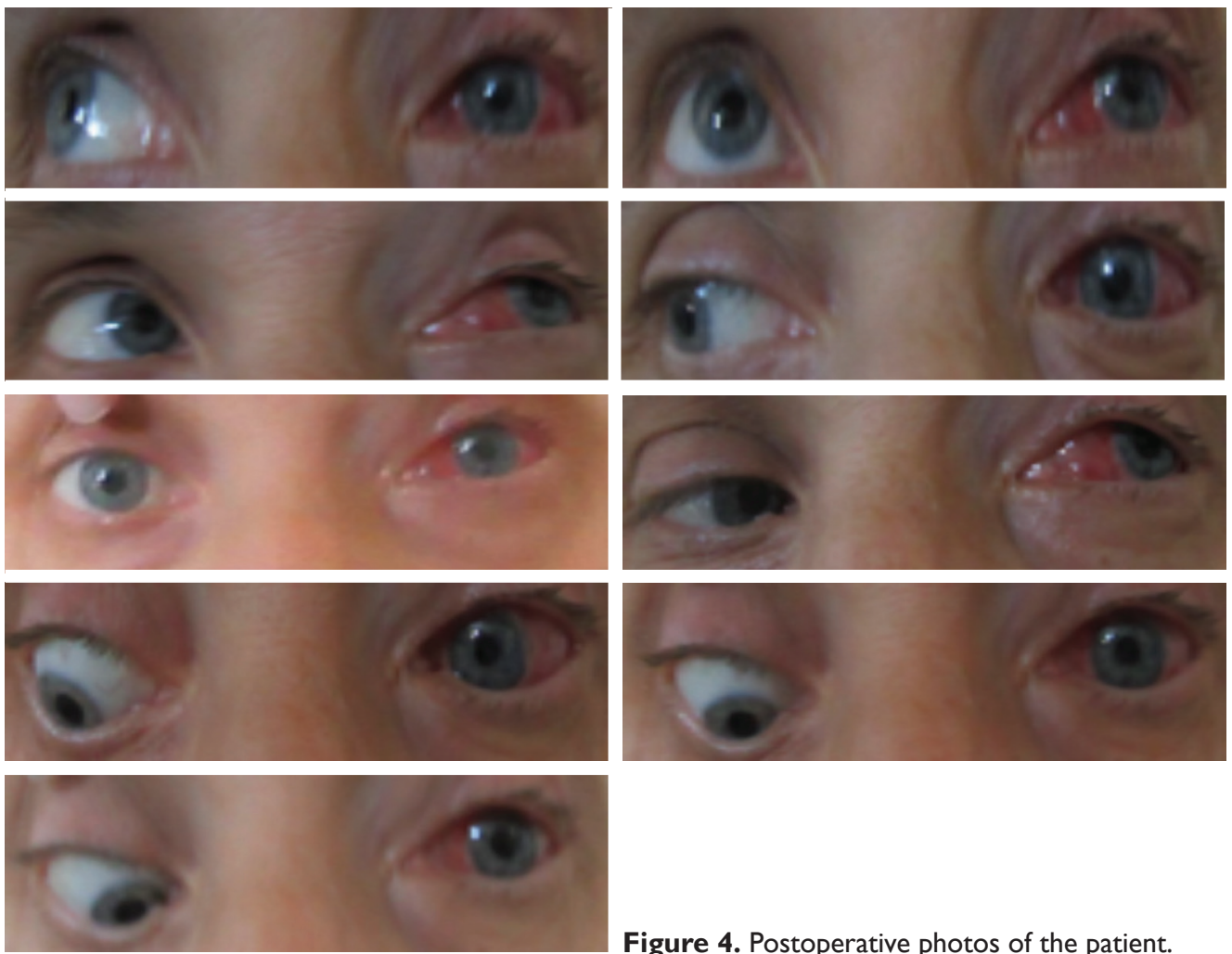

Figure 4. Postoperative photos of the patient.

of muscle $10 \mathrm{~mm}$ posterior to the insertions of the medial and lateral rectus muscles. The muscles were both then passed with partial and full thickness suture bites. Sutures were locked and locking bite was also secured with a twist lock. Approximately 8 to $10 \mathrm{~mm}$ posterior to the insertion of the superior rectus muscle, the medial and lateral rectus muscles were apposed with the help of the previously placed 6/0 Dacron sutures, tied and locked 3 times (Fig. 2). Scleral suture was not used at this stage. Then, $8 \mathrm{~mm}$ posterior to the insertion, one-third width of the superior rectus muscle was grasped centrally using partial and full thickness bites of 6/0 Dacron sutures, plication anteriorly, and sutured to the sclera I mm anterior to the insertion (Fig. 3). Conjunctiva was closed with 8/0 Vicryl (Ethicon, Inc., Somerville, NJ, USA) suture.

Postoperatively, elevation improved significantly and hypotropia was fully corrected (Fig. 4).

\section{Discussion}

Surgical treatment of superior branch of cranial third nerve palsy depends on the type and severity of the paralysis and the presence of other associated factors (2).

In the presence of superior rectus palsy, the preferred procedure is a Knapp transposition.

Knapp reported of 15 patients for whom correction of hypotropia ranged from 21 to 55 PD, with a mean of 38 PD.
Good results were obtained in 14 of 15 patients (3). Other authors have found similar rates of correction (4-9).

Mims reported 3 cases of isolated superior rectus palsy and performed 8 to $9-\mathrm{mm}$ recessions of the antagonist inferior rectus muscle for abnormal head tilt (10). Either Knapp procedure or augmented modifications (II) eliminate the hypotropia on effected eye similarly vertical rectus procedures on the fellow eye. But all these procedures needed many scleral suturations.

In this case, we preferred to perform muscle union surgery prior to the superior rectus application. While performing the transposition and union of the medial and lateral rectus muscles, we did not use a scleral suture. In addition to being just as effective as the Knapp procedure with or without augmentation we observed that this technique is easier and safer than Knapp procedure.

\section{Disclosures}

Peer-review: Externally peer-reviewed.

Conflict of Interest: None declared.

Authorship Contributions: Involved in design and conduct of the study (B.G.,S.C.); preparation and review of the study (B.G.,S.C.,A.I.); data collection (A.I.,S.C.).

\section{References}

I. von Noorden GK. Binocular Vision and Ocular Motility. Mosby: 2002. 
2. Singh A, Bahuguna C, Nagpal R, Kumar B. Surgical management of third nerve palsy. Oman J Ophthalmol 2016;9:80-6. [CrossRef]

3. Knapp P. The surgical treatment of double-elevator paralysis. Trans Am Ophthalmol Soc 1969;67:304-23.

4. Barsoum-Homsy M. Congenital double elevator palsy. J Pediatr Ophthalmol Strabismus 1983;20:|85-91.

5. Watson AG. A new operation for double elevator paresis. Trans Can Ophthalmol Soc 1962;25:182-7.

6. Cooper EL, Greenspan G. Operation for double elevator palsy. J Paediatr Ophthalmol Strabismus 1971;8:8-14.

7. Scott WE, Jackson $O B$. Double elevator palsy: the significance of inferior rectus restriction. Am Orthopt J 1977;27:5-10.

8. Caldeira JA. Vertical transposition of the horizontal rectus muscles for congenital/early onset "acquired" double elevator palsy: a retrospective long term study of 10 consecutive patients. Binocul Vis Strabismus Q 2000;15:29-38.

9. Kamlesh, Dadeya S. Surgical management of unilateral elevator deficiency associated with horizontal deviation using a modified Knapp's procedure. Ophthalmic Surg Lasers Imaging 2003;34:230-5.

10. Mims JL 3rd. Three Similar But Unique Cases Of Isolated Superior Rectus ExtraOcular Muscle (EOM) Palsy Strabismus, Presenting With Large Abnormal Head Tilts (Postures, AHP). Binocul Vis Strabolog Q Simms Romano 201 I;26:154-69.

I I. Snir M, Friling R, Kalish-Stiebel H, Bourla D, Weinberger D, Axer-Siegel R. Combined rectus muscle transposition with posterior fixation sutures for the treatment of double-elevator palsy. Ophthalmology 2005; I I 2:933-8. [CrossRef] 